\title{
Saúde mental no trabalho de segurança pública: estudos, abordagens e tendências da produção de conhecimento sobre o tema
}

Mental health in the public security workplace: studies, approaches and trends in the its production of knowledge

Salud mental en la seguridad pública: estudios, enfoques y tendencias de la producción del conocimiento de la temática

\author{
Regina Silva Futino ${ }^{1}$ \\ Maria Célia Delduque ${ }^{2}$
}

\begin{abstract}
Resumo
Objetivo: sistematizar estudos brasileiros sobre saúde mental no trabalho de segurança pública no período de 2007 a 2017. Metodologia: buscas em bancos de produção acadêmica nacionais e internacionais de acesso gratuito na internet. Resultados: deparouse com o predomínio de estudos voltados a servidores ligados à polícia militar e a leituras de gênero e suas repercussões na saúde das trabalhadoras, além de dados epidemiológicos relacionados ao estresse profissional. Conclusão: a noção de valorização do trabalhador desse segmento ainda é recente, com predomínio de estudos segmentados que não se aprofundam em uma abordagem sistêmica, o que abre oportunidade de novos estudos.

Palavras-chave: Saúde mental. Saúde do trabalhador. Polícia.
\end{abstract}

\begin{abstract}
Objective: organize Brazilian studies on mental health in the workplace of public security from 2007 to 2017. Methodology: research on national and international free access academic databases. Results: predominance of studies focused on police officers from the Brazilian military police and on gender studies and their repercussions on the female workers' health, in addition to epidemiological data related to professional stress. Conclusion: the notion of worker's valorization in this sector is still recent and shows superficial scientific production, which opens opportunities for further studies.
\end{abstract}

Keywords: Mental health. Occupational health. Police.

\section{Resumen}

Objetivo: sistematizar los estudios brasileños sobre salud mental en el trabajo de seguridad pública entre los años de 2007 a 2017. Metodología: búsqueda en base de datos de producción académicos nacionales e internacionales. Resultados: predominaron los estudios dirigidos a los empleados de la policía militar y las lecturas de género y sus repercusiones en la salud de los trabajadores, además de datos epidemiológicos y relacionados con el estrés profesional. Conclusión: la noción de valorar a las cuestiones

\footnotetext{
${ }^{1}$ Mestre em Saúde Coletiva; discente do Programa de Pós-graduação em Saúde Coletiva, Faculdade de Saúde, Universidade de Brasília, Brasília, Distrito Federal, Brasil. https://orcid.org/0000-0003-3890-3232. E-mail: reginafutino@gmail.com

2 Doutora; pesquisadora, Fundação Oswaldo Cruz, Programa de Direito Sanitário, Brasília, DF, Brasil. https://orcid.org/0000-0002-5351-3534.E-mail: mcdelduque@gmail.com
} 
generales de los trabajadores en ese segmento es aún reciente, con prioridad de estudios que no profundizan el enfoque sistémico, pero que abre oportunidades para futuros estudios.

Palabras clave: Salud mental. Salud laboral. Policía.

\section{Introdução}

Medo constante de errar, conviver simbioticamente com risco no trabalho e na região onde reside, possibilidade de ser morto no momento de folga, jornada de trabalho extenuante, sensação de desvalorização da profissão por distanciamento social, estigma de truculência e de abusos de poder no exercício profissional: esse é o rol de queixas e agravamentos mais comum de um fazer profissional de quem atua em segurança pública. Esses apontamentos são recorrentemente expostos nas diversas produções técnicas da área $(1,2)$. Este quadro é retroalimentado pelos agravantes números de violência da relação entre profissionais de segurança pública e sociedade, segundo dados comparados de 2017 em relação a 2015, divulgados pelo Fórum Brasileiro de Segurança Pública (FBSP). Nesse anuário de dados brasileiros na área de segurança pública, foi reportado que o país tem a polícia que mais mata no mundo - a letalidade policial aumentou 25,8\% -, mas também a que mais morre - 17,5\% a mais do que em $2015(3,4)$.

Somam-se esses dados de saúde e violência a outras informações controversas quando se trata do setor de segurança pública. Ao mesmo tempo em que os recursos públicos investido em políticas públicas da área diminuiu cerca de 10\% no período, o Brasil apresentou em 2016 mais de 61,5 mil assassinatos, o que corresponde aos números de mortos provocados pela explosão da bomba nuclear na cidade japonesa de Nagasaki durante a Segunda Guerra Mundial (3). Isto pode favorecer uma atuação profissional insegura de servidores do setor e outras repercussões - adoecimentos físicos e psicológicos, afastamentos por doenças relacionadas ao trabalho e repercussões duradouras na vida pessoal, familiar e social.

Nesse sentido, há uma corrente crescente de produções que tratam do nexo entre trabalho e as repercussões na saúde física e mental (5-9) em profissionais de uma forma geral e com recortes setoriais, como os trabalhadores de segurança pública $(1,2)$.Tais estudos encontram suporte em diretrizes internacionais $(10)$ e nacionais $(7,11,12)$.

Em detalhe, a saúde dos profissionais de segurança pública foi posta em agenda pública por meio de normas e de ações institucionais nos Estados e no Distrito Federal, bem como por ações no âmbito Federal, como a instituição em 2008 do Projeto Qualidade de 
Vida para profissionais de Segurança Pública pelo Ministério da Justiça (13). Essa política estabeleceu diretrizes nacionais de promoção e defesa dos direitos amplos dos profissionais de segurança pública pela Portaria Interministerial SEDH/MJ n. 2, de 15 de dezembro de 2010. Entretanto, tais ações ainda são incipientes perante a complexidade do quadro social brasileiro associado aos números de licenças e afastamentos em decorrência do trabalho em segurança pública, em especial os adoecimentos e agravamentos psicológicos, percebidos ao longo da produção científica nacional que será esmiuçado no decorrer deste estudo.

Ainda sobre essa saúde mental no trabalho em segurança pública (SMTSP), há uma diversidade de leituras e de inter-relações de saberes e de formas de atuação. Diversos métodos e abordagens foram adotados, e outros ainda serão elaborados e sistematizados para o estudo da relação trabalho, saúde mental, violência e segurança pública. Neste sentido, pretende-se estabelecer um panorama geral da produção de pesquisadores brasileiros do tema nos últimos 10 anos, compreendendo o período de 2007 a 2017- não se pretende aqui destrinchar minuciosamente e de forma exaustiva. Propõe-se nesse estudo uma sistematização de tendências de pesquisas e de possíveis lacunas de conhecimentos no tema, considerando a relevância do papel do trabalhador de segurança pública para implementação de políticas públicas e os reflexos na relação com a comunidade (14).

\section{Metodologia}

Este estudo exploratório foi estruturado como um levantamento bibliográfico de pesquisas e de publicações cientificas realizadas por pesquisadores brasileiros e divulgadas em banco de dados nacionais e internacionais com acesso virtual gratuito - Portal de periódicos da Coordenação de Aperfeiçoamento de Pessoal de Nível Superior (Capes), Biblioteca Virtual da Saúde na área de psicologia (BVS-Psicologia), PePsic, Scielo e Lilacs. Para o levantamento, foram estabelecidas buscas que contemplassem os campos de conhecimento das ciências da saúde e das ciências humanas e sociais em publicações aplicadas nos últimos 10 anos, do segundo semestre de 2007 ao primeiro semestre de 2017.

O perfil desta pesquisa pode ser percebido como um estudo de estado da arte ou estado do conhecimento. Segundo Almeida (15), estes estudos possuem caráter bibliográfico, desenhados para mapear e discutir um conjunto de produções acadêmicas em diferentes campos do conhecimento. Para tanto, foram utilizados em pesquisas delimitadas 
a produções nacionais os termos - em português, inglês e espanhol - Polícia, Bombeiro e Segurança Pública, combinados aos descritores Saúde Mental, Transtorno Mental, Estresse e Saúde do Trabalhador.

Quanto ao recorte para produções brasileiras, foi adotado pela especificidade do trabalho em segurança pública no Brasil, que se demonstrou particular quando contrastado com outros países, seja pelo perfil de trabalho $(3,4)$, seja pela questão identitária profissional $(1,2,16)$. Já o recorte temporal foi estabelecido pelo marco temporal da instituição do Projeto promovido pelo Ministério da Justiça em âmbito nacional para promoção de saúde do trabalhador (13) com propósito de fomento de projetos locais no tema e construção de sistematizações do adoecimento físico e mental no segmento.

Os artigos foram escolhidos por meio de uma leitura flutuante dos seus títulos e resumos com o intuito de separá-los daqueles que se diferenciavam do escopo do trabalho em segurança pública e das repercussões em saúde mental por esta atividade. Por escolha metodológica, foram delimitados os estudos com escopo da saúde mental de servidores ligados a Polícia Militar (PM), Polícia Civil (PC), Polícia Técnico-Cientifica (PTC) e Corpos de Bombeiros Militares (CBM), os estudos com os demais profissionais foram desconsiderados já na primeira leitura. Além disso, os estudos sobre violência e as repercussões na saúde da população em geral, formulação e validação de instrumentos de aferição de aspectos mentais e cognitivos de profissionais de segurança pública, políticas e práticas de combate às drogas e demais formas de dependência química e trabalhos em parceria com a segurança pública foram excluídos.

Após tal seleção, os artigos foram lidos em sua integralidade e sistematizados no programa Excel, versão 2016, nas seguintes categorias: Código (numeração automática); Título (título do artigo na totalidade); Tipo de publicação (artigo, tese ou dissertação); Palavras-chaves (palavras citadas no artigo); Autor (autor principal); Fonte (fonte de busca, banco de dados); Termo de busca principal (palavra motivadora da busca); Ano da publicação; Área de Conhecimento (Ciências da saúde e Ciências humanas e sociais aplicadas); Público-alvo (polícia civil, polícia militar, PTC e corpo de bombeiros). Desses artigos, somente 20 artigos da escolha da pesquisadora pelo critério de abrangência e pertinência ao tema saúde mental no trabalho em segurança pública foram selecionados para releitura aprofundada e produção de uma revisão temática de conteúdo para discussão deste estudo. 


\section{Resultados}

A partir da busca nas bases de dados do Portal de periódicos da Capes, foram encontradas um total de 455 produções (soma de todos artigos acadêmicos categorizados em bases diferentes). Após triagem com base em uma leitura dos títulos e resumos com enfoque na centralidade do tema de saúde mental e do trabalhador para o público alvo do estudo, foram selecionados 93 artigos. Neste momento, percebeu-se uma variedade de estudos sobre o trabalho da justiça, atividades de parcerias entre as instituições de segurança pública e diversos órgãos da administração direta em atividades de prevenção à violência e políticas relacionadas a drogas e outros vícios, e à percepção da população sobre o trabalho policial e ações públicas relacionadas.

De posse dos estudos, foi realizada uma nova leitura e somente 58 foram considerados aptos ao atender todos os critérios preestabelecidos na metodologia do estudo, dos quais 20 foram novamente revisados para produção das discussões deste estudo: estudos e público alvo brasileiro e ligados às instituições (PM, PC, CBM e PTC), período de publicação e indicação de resultados de pesquisa com diferentes recortes e abordagens teórico-metodológicas com correlação ao tema de estudo. Nesta triagem foram descartados os estudos de validação de instrumentos de mensuração de aspectos ligados à saúde mental, correlações genéricas ao militarismo e forças armadas, dentre outros. Esses quantitativos e etapas são detalhados na tabela 1.

Tabela 1. Procedimentos de busca e escolha de produções acadêmicas

\begin{tabular}{l|l|l|l}
\hline Etapa & Quantidade & \multicolumn{1}{|c}{ Ação } & \multicolumn{1}{c}{ Procedimento } \\
\hline 1 & 455 & $\begin{array}{l}\text { Busca ampliada nas } \\
\text { bases Scopus, } \\
\text { Lilacs, Psyclnfo, } \\
\text { Scielo, Pubmed } \\
\text { Leituras de títulos e } \\
\text { resumos }\end{array}$ & $\begin{array}{l}\text { Inclusão de estudos com temas de saúde } \\
\text { mental ou de saúde com repercussão em } \\
\text { saúde mental em profissionais de } \\
\text { segurança pública produzidos por } \\
\text { pesquisadores brasileiros }\end{array}$ \\
\hline 2 & 97 & $\begin{array}{l}\text { Leituras dos artigos } \\
\text { na integralidade }\end{array}$ & $\begin{array}{l}\text { Inclusão de estudos com afinidade em } \\
\text { saúde mental; os trabalhos somente } \\
\text { fisiológicos, de validação psicológica e que }\end{array}$ \\
\hline
\end{tabular}




\begin{tabular}{l|l|l|l}
\hline & & & $\begin{array}{l}\text { compreendessem outros profissionais de } \\
\text { saúde foram escolhidos }\end{array}$ \\
\hline 3 & 58 & $\begin{array}{l}\text { Leitura e escolha } \\
\text { temáticas de análise }\end{array}$ & $\begin{array}{l}\text { Compilação de informações obtidas nas } \\
\text { produções para delineamento do texto }\end{array}$ \\
\hline 4 & 20 & $\begin{array}{l}\text { Escolha de produção } \\
\text { por tema }\end{array}$ & $\begin{array}{l}\text { Revisão temática para produção de } \\
\text { conteúdo para discussão }\end{array}$ \\
\hline
\end{tabular}

Fonte: elaboração das autoras.

Quanto à distribuição da população alvo dos estudos, foram constatados que aproximadamente $57 \%$ das pesquisas abordavam questões de SMTSP em profissionais da Polícia Militar - os estudos focados especificamente nos profissionais da Polícia Civil e Corpo de Bombeiros Militar compreendem em somente 5\% da amostra e não foram encontrados estudos específicos para os servidores da Polícia Técnica-Cientifica. Mas cabe esclarecer que a organização das instituições é de responsabilidade constitucional das Entidades Federativas, e, portanto, algumas das instituições militares (PM e CBM) e as polícias de investigação (PC e PTC) são unificadas, o que pode trazer luz a possíveis existências de estudos com mais de um público alvo ou estudos com instituições unificadas.

Outro fator que chama a atenção é a diversidade de termos chaves para os estudos encontrados e a variedade de abordagens e arcabouços teóricos utilizados nos estudos. Seligmann-Silva (5), Jacques (7) e Araújo (17) mencionam que nos estudos de saúde mental e trabalho são comuns diferentes abordagens teórico-metodológicas e a diversidade taxonômica, com agrupamentos, distinções e classificações variadas. Seligmann-Silva (5) até correlaciona esta variabilidade a dificuldades de unificar conhecimentos para o estabelecimento de consensos em termos de classificação, mas ressalta que este retrato traz uma natureza científica e de ordem sociopolítica correlacionada aos desafios da interdisciplinaridade e das recorrentes transformações do mundo. Estes autores distinguem pelo menos três modelos teóricos metodológicos distintos $(5,17)$, sendo que Jacques $(7)$ acrescenta um quarto:

1) Teoria do estresse: termo popularizado por uma polissemia conceitual com concepções cognitivo-comportamental e do senso comum, sendo também associada a Síndrome de burnout e aos estudos de fadiga no trabalho, onde são comuns as pesquisas para classificação do estresse em fases de acordo com os níveis e respostas aos enfrentamentos e de adaptação aos processos de trabalho pelo sujeito ou grupo; 
2) Psicodinâmica do trabalho: abordagem subsidiada nos estudos de Dejours (18) que estuda o prazer-sofrimento no contexto de trabalho com aportes psicanalíticos no reconhecimento do processo do adoecimento mental e de seus entraves em relação à organização de trabalho tanto no nível individual, quanto no coletivo;

3) Estudos de subjetividade no trabalho: onde o trabalhador é visto pela ótica de suas experiências no mundo do trabalho e a organização - e seu caráter técnico-socialeconômico - é fator influenciador de sua condição de saúde; e,

4) Estudos epidemiológicos: abordagem historicamente influenciada pelos estudos de Ramazzini, que originou os estudos de doenças correlacionadas ao ambiente de trabalho os pesquisadores usam instrumentos de aferição para mensurar adoecimentos, seja inicialmente focado em saúde mental, seja em saúde física com repercussões psíquicas.

Isto posto, na revisão das produções estudadas, notou-se uma sobreposição de abordagens. No entanto, os textos que ficaram mais próximos as classificações apresentadas pelos autores foram dos estudos que utilizaram a teoria do estresse. Nestes estudos, os grupos profissionais são abordados por meio de instrumentos de mensuração predominante quantitativo para classificação em fases de enfrentamento do estresse, e, de posse da distribuição dos profissionais nos perfis de estresse, são verificados também fatores estressores para construção de leituras em termos de ocorrência de sintomas físicos e psicológicos característicos no contexto daquela população. Assim, para além das abordagens técnico-metodológicas, tal diversidade de estudos é demonstrada na variabilidade de descritores e de temas conforme tabela 2.

Tabela 2. Diversidade taxonômica e distribuição de ocorrências

\begin{tabular}{l|l}
\hline $\begin{array}{l}\text { Segmentos por } \\
\text { ocorrências }\end{array}$ & \multicolumn{1}{c}{ Descritores } \\
\hline & $\begin{array}{l}\text { Saúde mental; saúde mental e trabalho; taxas de suicídio; } \\
\text { suicídio; suicídio policial; ideação suicídio; sofrimento psíquico; } \\
\text { uso de tranquilizantes; uso de drogas; uso de bebida alcoólica; } \\
\text { trauma; transtornos mentais; transtornos dissociativos; sistema } \\
\text { límbico; bem-estar; avaliação psicológica; autoestima; } \\
\text { psicopatologia; depressão; espessura cortical; consumo de } \\
\text { ocorrências) } \\
\text { substâncias psicoativas; apoio psicológico; ansiedade }\end{array}$ \\
\hline
\end{tabular}


Saúde, Saúde do

Trabalhador e Saúde

Pública

(33 ocorrências)
Saúde; saúde do trabalhador; saúde do policial; saúde pública; prevenção; epidemiologia; prevalência; risco epidemiológico; sinais e sintomas; doença ocupacional; adoecimento no trabalho; doença cardíaca; composição corporal; cansaço físico; cansaço emocional; estilo de vida; bruxismo; atividade motora; absenteísmo

Estresse; estressores; estresse psicológico; estresse policial; estresse ocupacional; estresse no trabalho; estresse fisiológico; estresse profissional; síndrome de burnout; transtorno de estresse pós-traumático; coping

Estresse
( 25 ocorrências gerais,
sendo 20 para
estresse)
$\begin{aligned} & \text { Qualidade de Vida (12 } \\ & \text { ocorrências) }\end{aligned}$

Qualidade de vida no trabalho; qualidade de vida

Segurança pública; trabalho; trabalho policial; trabalho de resgate; violência; violência contra idoso; atividades militares; valorização policial; satisfação no trabalho; identidade profissional; identidade; imagem; relações interpessoais; apoio social; apoio institucional; vitimização; riscos; risco social; organização do trabalho; cultura organizacional; condições de trabalho; comprometimento; estilo de vida

Outras abordagens

(1 ocorrência)

Psicodinâmica do trabalho

\begin{tabular}{l|l}
\hline $\begin{array}{l}\text { Demais } \\
\text { ocorrências }\end{array}$ & \multicolumn{1}{c}{ Descritores } \\
\hline $\begin{array}{l}\text { População } \\
\text { (56 ocorrências) }\end{array}$ & $\begin{array}{l}\text { Polícia; policial militar; policial civil; oficiais de polícia; mulheres } \\
\text { policiais; mulheres; militares; família do policial; família; } \\
\text { bombeiros militares; gênero e identidade de gênero }\end{array}$ \\
\hline $\begin{array}{l}\text { Outros } \\
\text { (9 ocorrências) }\end{array}$ & $\begin{array}{l}\text { Subjetivo; status nutricional; idoso; estudo de casos; mobilidade; } \\
\text { envelhecimento; enfermeiro; educação física; Brasil; afeto }\end{array}$ \\
\hline
\end{tabular}

Fonte: elaboração das autoras.

Vale esclarecer que a busca de artigos não teve como recorte a análise de políticas públicas, projetos e ações institucionais com enfoque de pesquisa, buscando somente as produções e estudos sobre a saúde mental em uma categoria profissional específica. Apesar de menções mínimas de atividades institucionais no decorrer dos artigos consultados, a leitura de ações estruturadas para prevenção de adoecimentos e promoção de saúde integral deste perfil de servidor e a construção de estudos avaliativos ficará para futuras oportunidades e como sugestão para demais pesquisadores. 


\section{Discussões}

A atividade em segurança pública é singular quando percebida como uma atividade em que risco não é uma mera possibilidade de acidente de trabalho, e sim como fator estruturante de suas relações, do seu ambiente laboral e de condições de desenvolvimento funcional. Este risco, segundo Minayo (16) e Adorno (19), também deve ser levado em conta na análise do contexto, bem como na observação de seus aspectos epidemiológicos - em termos de perigos e locais de fatalidades - e sociais - pela capacidade de afrontamento a situações reais e imaginárias relacionadas ao trabalho. Para além das mortes e acidentes em decorrência do trabalho, esses profissionais também são vitimados em horários de folga pela sua associação institucional ou atividades extras, como seguranças privados, por exemplo. Condiciona-se, aqui, que a leitura do termo vitimizar ou vitimização é influenciado por Minayo(16) quando a autora afirma que tal conceito "se materializa em traumas, lesões ou mortes ocorridas na defrontação com a criminalidade e na manutenção da ordem".

Esta sensação de insegurança e as exigências de atuação frente ao quadro de violência brasileiro atual acarreta ao segmento profissional sobrecargas e sofrimento psíquico $(16,20)$. Sobre os números de prevalência em sofrimento mental, o estudo de Souza (20) realizado em 2012 com policiais militares do Estado do Rio de Janeiro obteve um percentual de 35,7 da amostra de 1.120 trabalhadores. Nesta amostra, ainda há apontamentos de baixos índices de grau de satisfação com sua qualidade de vida, somente $26 \%$ relatou estar satisfeito, além de queixas com as condições de saúde física e mental, de estresse nas atividades e a vitimização como fatores que influenciam o sofrimento psíquicos destes trabalhadores. Este quadro também influencia em termos de afastamentos para tratamento relacionados a Transtorno Mental e Comportamental (TMC) - a Polícia Militar de Santa Catarina, por exemplo, apresentou $24 \%$ de notificações deste perfil de licenças somente no ano de 2012 (21). Em termo de afastamentos, voltando ao Estado do Rio de Janeiro, só em 2016 foram concedidas 1.398 licenças psiquiátricas para um efetivo de aproximadamente 21.500 PMs (6,48\% afastados) segundo reportagens de mídia de massa (22). 
Dos estudos de estresse, há apontamentos para ocorrência de repercussões à saúde pelo estresse em grande parte do efetivo da Polícia Militar, como predominância de sintomas físicos assinalados (23). No que tange as fases, a resistência $(24,25)$ e o alerta (23) são destacadas nestes estudos. A saber das fases e seus sintomas, as autoras mencionam e utilizam a seguinte classificação e evolução de sintomatologia:

1) fase de alerta se caracteriza por reações fisiológicas (taquicardia, sudorese) e relaciona-se a reação e fuga instintiva (26) e ao momento em que o "organismo é exposto a uma situação de tensão e se prepara para a ação" (24);

2) fase de resistência é percebida pela permanência do estresse e da adaptação do organismo à situação (26), com possibilidade de sensação de desgaste generalizado e repercussões em aspectos cognitivos (24);

3) fase de exaustão, o processo estressor continuado encontra uma reação adaptativa do organismo e assim, doenças somáticas costumam a aparecer (26); e,

4) fase de exaustão está associada à exaustão nos aspectos psicológico e físicos e é comum estar associado inclusive até ao falecimento do trabalhador (24).

Mesmo distante do contexto de trabalho ostensivo da Polícia Militar, os profissionais da Polícia Civil também relatam problemas relacionados ao estresse semelhantes, quando os impactos na saúde são vistos pelo viés do estresse e dos seus fatores desencadeadores no contexto de trabalho. Tais estudos apontam que o excesso de trabalho, a infraestrutura ineficiente e as relações profissionais são fatores percebidos negativamente pelos profissionais (27). No que tange aos afastamentos do trabalho por transtornos mentais e comportamentais, Castro (28), em estudo publicado em 2015, aponta que, de cem trabalhadores de Policial Civil de Santa Catarina, 4,6\% são afastados em algum momento de sua vida funcional e o fator de tempo de atividade (antiguidade funcional) influencia em termos de maior concentração em faixas mais avançadas. Para lidar com estresse, os trabalhadores utilizam-se de estratégias como esquiva (evitar de levar problemas para o contexto familiar), de "autocontrole, apoio da família, lazer, prática de exercícios, apoio na religião e atitude positiva" (27).

A similaridade das instituições policiais são alentadas por outros estudos realizados em instituições de segurança pública do Rio de Janeiro $(29,30)$, que se reforçam a questão do risco e de sofrimento durante desenvolvimento de atividades laborais e nos momentos de folga - os policiais civis associam suas queixas à possibilidade de serem vitimados ou 
sofrerem danos na sua condição física e psicológica. As condições de saúde física e os problemas do sistema nervoso também estão relatados na questão de sofrimento mental (30). Para enfrentamento dos riscos, os trabalhadores lançam as seguintes estratégias de contraposição às possibilidades de adoecimentos: "mudança na rotina e no estilo de vida; naturalização e banalização do risco; fé e misticismo e apoio dos pares" (29).

Destas estratégias de enfrentamento dos fatores aversivos à saúde mental, a crença da autoeficácia como facilitador do processo de saúde e mediação do contexto de trabalho foram abordados em estudos $(21,31,32)$ com análises antagônicas. Em Souza e autores (31), a influência preditiva da autoeficácia pode auxiliar na avaliação de bem-estar subjetivo do policial militar e seu treinamento deve ser incluso como um mecanismo de auto regulação para controle de hábitos saudáveis e manutenção da qualidade de vida. Já Coelho e colaboradores (32) apresentam ressalvas na correlação da autoeficácia e sua influência na qualidade de vida do trabalho do PM, orientado a revisão do foco da manutenção da saúde como uma questão individual do trabalhador para reformulação dos processos da organização de trabalho mais saudáveis.

Outrossim, no que tange ao estudo de gênero na atuação em segurança pública, é relatado que as mulheres do segmento são mais acometidas por estresse $(20,24,25,33)$ e apresentam graus de insatisfação na percepção da qualidade de vida no trabalho (34). Tais fatores estão relacionados a questões de gestão e de relações institucionais $(25,33,34)$, com o agravante de menções de discriminação de gênero e assédio como fatores que influenciam o estresse (33). Não é de todo modo estranho a existência e o registro de tais dados: estas mulheres concentram as singularidades e os agravantes próprios do trabalho feminino e do trabalho em segurança pública. Ou seja, além das questões de dupla jornada e de divisão sexual do trabalho própria dos estudos do trabalho feminino, estas trabalhadoras são condicionadas a negar diferenças de gênero para obter reconhecimento entre pares, sendo comuns relatos de violações de direitos e tensões por imposições hierárquicas das instituições (35).

De modo geral, as mulheres na segurança pública não representam um efetivo nacional significativo nas instituições, sendo, aproximadamente, 30\% da PC, 10\% na PM e $7 \%$ do CBM (36). Tal fator pode ser associado à inserção recente no histórico das instituições. As profissionais do segmento foram inseridas em meados da década de 1980 como resposta ao processo de redemocratização do País e para atendimento de uma 
proposta de amenizar a imagem institucional e de executar ações voltadas a públicos vulneráveis, como idosos, mulheres e crianças $(33,35,37)$. Entretanto, cabe atenção e o alerta a esta disparidade entre gênero, trabalho e perfil profissional, uma vez que pesquisas apontam os impactos e diferenças em tratos inter-relacionais (33, 35, 37). Nesse quesito, exemplificam-se dados levantados no estudo sobre mulheres na segurança pública (38), que aponta a dificuldade de mobilidade e reconhecimento na carreira. As mulheres respondentes do estudo mencionam também que já experimentaram algum tipo de assédio, moral ou sexual, dentro de sua instituição (39,2\%) - em 74,1\% desses casos, os autores/responsáveis estão associados a postos de superiores hierárquicos.

Num grau extremo dos impactos na saúde mental do trabalho em segurança pública, chamam a atenção os estudos sobre ideação suicida no segmento. O tema não foi o enfoque da pesquisa, mas a questão do suicídio policial (39) tem sido recorrente na mídia de massa quando discutidos os números de vitimização, o que aponta para futuras possibilidades de estudos e propostas de intervenção. Miranda e colaboradores (40), relatam que a temática afeta mais as mulheres, com tentativas em momentos de folgas e recorrentes relatos de sofrimento e desvalorização profissional. A autora evidencia, na amostra de sua pesquisa, os fatores associados ao comportamento suicida em quatro níveis de análise e possibilidade de intervenção: (i) organizacional, sendo a satisfação profissional importante fator protetivo; (ii) situacional, onde os cuidados aos fatores de exposição de vitimização direta e indireta devem ser calculados quanto a sua vulnerabilidade; (iii) social, que propicia ao cuidado com a questão de valorização e desconfiança nas relações intra e extra instituição; e, (iv) individual, em que as questões singulares de saúde física e mental devem ser aportados e examinados.

Para além da atividade policial, os bombeiros militares, em específico, relatam que a sobrecarga de trabalho provocada por escalas de trabalho extenuantes, as relações profissionais e as influências do militarismo na atividade também são associadas ao sofrimento mental (41-43). Mas, ao contrário de seus colegas policiais militares, o reconhecimento e valorização da imagem do bombeiro perante a comunidade é considerada como fator de orgulho e prazer no trabalho (41-43). Sobre a questão da desvalorização da imagem policial há uma associação quanto ao histórico de confrontação com a população em geral e os números de vítimas $(3,4,19)$, bem como a atribuição da guarda da ordem e de controle de situações adversas. 
Frente à realidade laboral descrita nos estudos, os pesquisadores sugerem intervenções que prevejam mudanças nos processos de trabalho como um todo, considerando-se as relações entre os profissionais e suas intuições (32), bem como ações específicas focadas nos aspectos psicológicos e de treinamento (27, 28, 44). Debate-se também as ideias de valorizar o profissional além de suas atividades, dentro e fora de seu contexto de trabalho (19).

\section{Considerações finais}

A noção de direitos humanos e a sua compatibilidade com a atividade em segurança pública e a valorização do seu profissional é ainda recente na história e nas práticas da Administração Pública Federal, e teve como marcos o lançamento do Plano Nacional de Segurança Pública, a instituição do Fundo Nacional de Segurança Pública, em 2000, e criação e implementação do Sistema Único de Segurança Pública (SUSP) por meio de Lei n. 13.675, de 11 de junho de 2018. Esta mudança de paradigma trouxe um olhar para o capital humanos destas instituições por meio de ações sistemáticas de fomento a modernização das instituições e promoção da valorização profissional por meio de parcerias União-Estados-Municípios na implementação de projetos locais em ensino e saúde do trabalhador (45).

Cano e colaboradores (46) complementam que a noção de valorização da condição individual do trabalho em segurança pública e a promoção dos direitos destes servidores ainda é um processo em construção, com predomínio de ações institucionais isoladas e políticas públicas em desenvolvimento e consolidação. Valorizar o trabalhador, como lhe assegurar condições plenas de execução de suas funções, é promover sua saúde física e mental e sua garantia e acesso a diretos. Tal como a atenção à saúde física e mental, cabe ressaltar a importância de diretrizes nacionais para garantia de direitos à diversidade, à participação cidadã, à valorização da vida por meio de equipamentos de proteção individuais adequados as funções, tal como preconizado na Portaria Interministerial SEDH/MJ n.2/2010.

A capacidade do trabalhador executar suas funções é dinâmico e depende de sua saúde - seu estado bem-estar físico, mental e social total, tal como definido pela Organização Mundial da Saúde. A percepção do trabalhador que não adoece é forte e o cuidado com a saúde mental em segurança pública ainda é tratado como um tabu (47). Além disso, estudos apontam para a necessidade de perceber o profissional para além de suas 
funcionalidades e responsabilidades pela instituição $(19,46)$ e que as instituições de segurança pública ainda não se adequaram às mudanças preconizadas pela Constituição cidadã no que tange ao reconhecimento de direitos, estando ainda condicionadas a ranços do militarismo quanto a percepção do indivíduo que atua em segurança pública.

Tal como discutido, não foram mobilizados e revisados estudos de casos ou análises de ações institucionais para promoção da saúde funcional do segmento. Os estudos analisados nesse texto focam a relação da saúde mental com os aspectos próprios da atividade e da relação trabalhador-organização do trabalho. Entretanto, o olhar da saúde mental ainda recaí na questão individual do trabalhador, ao passo que os processos de trabalho e o perfil institucional são tratados como um dos demais fatores de adversidade. Ressalta-se, nesse contexto, as contribuições de Cano e colaboradores (46) sobre revisões de práticas e instruções institucionais que permitam transparência e a participação dos trabalhadores nos debates e nas formulações de políticas, favorecendo ambientes laborais promotoras de saúde.

Por fim, reuniu-se um conjunto de estudos segmentados sobre a saúde mental de um trabalhador específico, numeroso e relevante em sua relação social e em função da execução de políticas públicas. Mas, também, esse estudo encontrou informações sistematizadas sobre profissionais afastados por questões laborais ligados à sua saúde mental, com relatos sobre depressão, exaustão ou estresse, queixas de assédio moral e sexual, sofrimento psíquicos e ideias suicidas. Sendo a saúde um direito, ressalta-se a importância da proteção e promoção da saúde mental no trabalho em segurança pública, seja por meio de políticas públicas, seja por estudos. Desse modo, dado o caráter ainda inovador, atenta-se à necessidade de estudos que tragam um panorama nacional da saúde desse trabalhador, bem com avaliações de efetividade com caráter longitudinal das intervenções já realizadas.

\section{Referências}

1. Minayo MCS, Souza ER, Constantino P. Missão Prevenir e Proteger: condições de vida, trabalho e saúde dos policiais militares do Rio de Janeiro. Rio de Janeiro: Fiocruz; 2008. $328 \mathrm{p}$.

2. Minayo MCS, Souza ER. Missão Investigar: entre o ideal e a realidade de ser policial. Rio de Janeiro: Garamond; 2003. 351 p. 
3. Lima RS, Bueno S, Martins C, Neme C, Marques D, Sobral I, et al. $11^{\circ}$ Anuário brasileiro de segurança pública 2017 [Internet]. São Paulo; 2017 [cited 2020 May 21]. Available from: www.forumseguranca.org.br

4. Sergio de Lima Samira Bueno Luis Iván Valencia Olaya Hanashiro Pedro Henrique Machado Adriana dos Santos Lima RG, Gomide A, Schmidt F, Guedes E, Ferreira H, Cunha A, et al. Atlas da Violência 2017 [Internet]. Rio de Janeiro; 2017 [cited 2020 May 21]. Available from: http://www.forumseguranca.org.br/wpcontent/uploads/2017/06/FBSP_atlas_da_violencia_2017_relatorio_de_pesquisa.pdf

5. Seligman-Silva E. Psicopatologia e saúde mental no trabalho. In: Atheneu, editor. Patologia do Trabalho. 2nd ed. São Paulo; 2003. p. 1141-82.

6. Seligman-Silva E. Desgaste mental no trabalho dominado. Rio de Janeiro: UFRJ; Cortez; 1994. 293 p.

7. Jacques MGC. "Doença dos nervos": uma expressão da relação entre saúde / doença mental. In: Saúde mental \& trabalho: leituras. 2nd ed. Petropolis - RJ: Vozes; 2002. p. 98111.

8. Jacques MGC. Abordagens teórico-metodológicas em saúde/doença mental \&amp; trabalho. Psicol Soc [Internet]. 2003 Jan [cited 2017 Nov 28];15(1):97-116. Available from: http://www.scielo.br/scielo.php?script=sci_arttext\&pid=S0102-

$71822003000100006 \&$ Ing=pt\&tlng=pt

9. Glina DMR, Rocha LE. Saúde mental no trabalho - da teoria à prática. São Paulo: Roca; 2016. 444 p.

10. International Labour Office. Compendium of international labour conventions and recommendations Compilation of international labour Conventions and Recommendations [Internet]. Geneva; 2015 [cited 2017 Dec 6]. Available from:

http://www.ilo.org/wcmsp5/groups/public/---ed_norm/---

normes/documents/publication/wcms_413175.pdf

11. Ministério do Planejamento, Orçamento e Gestão. Portaria n ${ }^{\circ} 1.261$ de 05 de maio de 2010 [Internet]. DOU de 06/05/2010 Brasil; 2010. Available from:

http://www.trtsp.jus.br/geral/tribunal2/ORGAOS/Min_Div/MPOG_Port1261_10.html

12. Ministério da Saúde. Portaria n 1.823, de 23 de agosto de 2012 [Internet]. Diario Oficial da União Brasil; 2012. Available from:

http://www.conselho.saude.gov.br/web_4cnst/docs/portaria_1823_12_institui_politica.pdf

13. Paulo L, Ferreira Barreto T, Brisolla Balestreri R, Ferreira LA, Barroso JM. Vade

Mecum: Segurança Pública [Internet]. Brasília, DF; 2010 [cited 2017 Dec 6]. Available from: http://www.mj.gov.br/senasp

14. Lipsky M. Burocracia de nível de rua: dilemas do indivíduo nos serviços públicos. ENAP, editor. Brasília; 2019. 
15. Almeida NSF. As pesquisas denominadas \&quot;Estado da Arte\&quot; Educ Soc [Internet]. 2002 [cited 2017 Dec 6];79:257-72. Available from:

http://www.scielo.br/pdf/es/v23n79/10857.pdf

16. Minayo M, Souza E, Constantino P. Riscos percebidos e vitimização de policiais civis e militares na (in) segurança pública. Cad saude publica [Internet]. 2007;23(11):2767-79.

Available from: http://bases.bireme.br/cgi-

bin/wxislind.exe/iah/online/?IsisScript=iah/iah.xis\&src=google\&base=LILACS\&lang=p\&next Action=Ink\&exprSearch=465155\&indexSearch=ID

17. Araujo TM. Revisão de abordagens teórico-metodológicas sobre saúde mental trabalho. In: Saúde do trabalhador na sociedade brasileira contemporânea. Rio de Janeiro: Fiocruz; 2011. p. 325-44.

18. Dejours C. A loucura do trabalho: estudo de psicopatologia do trabalho. $5^{\text {a }}$. São Paulo: Oboré; 1992. $168 \mathrm{p}$.

19. Minayo MCS, Adorno S. Risco e (in)segurança na missão policial. Cien Saude Colet [Internet]. 2013;18(3):585-93. Available from:

http://www.scielo.br/scielo.php?script=sci_arttext\&pid=S1413-

$81232013000300002 \& \operatorname{lng}=p t \& t \operatorname{lng}=p t$

20. Souza ER, Minayo MCS, Silva JG, Pires TO. Fatores associados ao sofrimento psíquico de policiais militares da cidade do Rio de Janeiro, Brasil. Cad Saude Publica [Internet]. 2012 Jul [cited 2017 Dec 6];28(7):1297-311. Available from:

http://www.scielo.br/scielo.php?script=sci_arttext\&pid=S0102-

311 X2012000700008\&lng=pt\&tlng=pt

21. Lima VP, Blank LG, Menegon FA. Prevalência de Transtorno Mental e Comportamental em Policias Militares/SC, em Licença para Tratamento de Saúde Prevalence of Mental and Behavioral Disorders in Military Police of Santa Catarina. Psicol Ciência E Profissão. 2015;35(3):824-40.

22. Briso CB, Bottari E, Amin J. Em apenas um ano, PM concedeu 1.398 licenças psiquiátricas [Internet]. 2017. Available from: https://oglobo.globo.com/rio/em-apenas-umano-pm-concedeu-1398-licencas-psiquiatricas-20847028

23. Gleiber Couto A, Brito EAG, Vasconcelos-Silva A, Lucchese R. Saúde mental do policial militar: Relações interpessoais e estresse no exercício profissional. Psicol Argum Curitiba. 2012;30(68):185-94.

24. Dantas MA, Brito DVC, Rodrigues PB, Maciente TS. Avaliação de estresse em policiais militares. Psicol Teor e prática [Internet]. 2010 [cited 2017 Dec 6];12(3):66-77. Available from: http://pepsic.bvsalud.org/scielo.php?script=sci_arttext\&pid=S151636872010000300006 
25. Pinheiro LRS, Farikoski C. Avaliação do Nível de Estresse de Policiais Militares. Rev Psicol da IMED [Internet]. 2016 Jun 30 [cited 2017 Dec 6];8(1):14-9. Available from: https://seer.imed.edu.br/index.php/revistapsico/article/view/1250

26. Lipp MN, Malagris LN. O Stress Emocional e seu Tratamento. São Paulo: Artes Médicas; 2001.

27. Dela Coleta ASM, Dela Coleta MF. Fatores de estresse ocupacional e coping entre policiais civis. 2008 [cited $2017 \mathrm{Dec} 6] ; 13(13434): 59-68$. Available from:

http://www.scielo.br/pdf/pusf/v13n1/v13n1a08.pdf

28. Castro MCD, Cruz RM, Castro MCD, Cruz RM. Prevalência de Transtornos Mentais e Percepção de Suporte Familiar em Policiais Civis. Psicol Ciência e Profissão [Internet]. 2015 Jun [cited 2017 Dec 6];35(2):271-89. Available from:

http://www.scielo.br/scielo.php?script=sci_arttext\&pid=S1414-

98932015000200271\&lng=pt\&tlng=pt

29. Constantino P, Ribeiro AP, Correia BSC. Percepção do risco entre policiais civis de diferentes territórios do Estado do Rio de Janeiro. Cien Saude Colet [Internet]. 2013 Mar [cited 2017 Dec 6];18(3):645-55. Available from:

http://www.scielo.br/scielo.php?script=sci_arttext\&pid=S1413-

$81232013000300010 \& \operatorname{lng}=$ pt\&tIng=pt

30. Souza ER, Figueiredo AEB, Pinto LW. Sofrimento psíquico em policiais civis do Estado do Rio de Janeiro. Ciência e Saúde Coletiva [Internet]. 2013;38(3):633-44. Available from: http://www.scielosp.org/scielo.php?script=sci_arttext\&amp\%5Cnpid=S141381232013000800009

31. Souza LAS, Torres ARR, Barbosa GA, Lima TJS, Souza LEC. Self-efficacy as a mediator of the relationship between subjective well-being and general health of military cadets. Cad Saude Publica [Internet]. 2014;30(11):2309-19. Available from: http://www.scielo.br/scielo.php?script=sci_arttext\&pid=S0102$311 \times 2014001102309 \&$ Ing=en\&tIng=en

32. Coelho E, Antloga C, Maia M, Takaki K. Autoeficácia e Qualidade de Vida no Trabalho: um estudo com policiais militares. Psicol Teor e Pesqui [Internet]. 2016;32(spe):1-7. Available from: http://www.scielo.br/scielo.php?script=sci_arttext\&pid=S0102$37722016000500219 \&$ lng $=$ pt\&tIng=pt

33. Bezerra CM, Minayo MCS, Constantino P. Estresse ocupacional em mulheres policiais. Cien Saude Colet [Internet]. 2013 Mar [cited 2017 Dec 6];18(3):657-66. Available from: http://www.scielo.br/scielo.php?script=sci_arttext\&pid=S1413$81232013000300011 \& \operatorname{lng}=$ pt\&tIng=pt

34. Pitts PF, Ferraz SB, Lima TCB. Qualidade de vida no trabalho: um estudo com mulheres na polícia militar. Diálogo [Internet]. 2014 Dec 17 [cited 2017 Dec 6];0(27):57-73. Available from: http://www.revistas.unilasalle.edu.br/index.php/Dialogo/article/view/1698 
35. Ministério da Justiça. Mulheres na segurança pública [Internet]. Brasília; 2013 [cited 2017 Dec 6]. Available from: http://www.justica.gov.br/sua-seguranca/segurancapublica/analise-e-pesquisa/download/estudos_diversos/4mulheres-na-segurancapublica.pdf

36. Ministério da Justiça. Pesquisa perfil das Instituições de Segurança Pública [Internet]. Brasília ; 2013 [cited 2017 Dec 6]. Available from: http://www.justica.gov.br/suaseguranca/seguranca-publica/analise-e-pesquisa/download/pesquisaperfil/relatorio_pesquisa_perfil_anobase_2012.pdf

37. Calazans ME. Mulheres no policiamento ostensivo e a perspectiva de uma segurança cidadã. São Paulo em Perspect [Internet]. 2004 Mar [cited 2017 Dec 6];18(1):142-50. Available from: http://www.scielo.br/scielo.php?script=sci_arttext\&pid=S0102$88392004000100017 \&$ lng $=$ pt\&tIng=pt

38. Bueno S, Lima RS, Tonelli MJ, Santos T, Ribeiro L, Alcadipani R, et al. As mulheres nas instituições policiais [Internet]. São Paulo; 2015 [cited 2018 Jul 11]. Available from: http://www.forumseguranca.org.br/storage/publicacoes/FBSP_Mulheres_instituicoes_polici ais_2015.pdf

39. Miranda D, Guimarães T. O suicídio policial: O que sabemos? Dilemas [Internet]. 2016 [cited 2017 Dec 6];9:1-18. Available from:

https://revistas.ufrj.br/index.php/dilemas/article/viewFile/7680/6191

40. Miranda D, Borges D, Cano I, Guimarães T, Novaes F, Ribeiro MS, et al. O comportamento suicida entre profissionais de segurança pública e prevenção no Brasil. In: Direitos humanos, grupos vulneráveis e segurança pública [Internet]. Brasília: Ministério da Justiça; 2016 [cited 2017 Dec 6]. p. 151-202. Available from: http://www.justica.gov.br/suaseguranca/seguranca-publica/analise-e-

pesquisa/download/estudos/pspvolume6/o_comportamento_suicida_entre_profis_sp_preve ncao_brasil.pdf

41. Monteiro JK, Maus D, Machado FR, Pesenti C, Bottega D, Carniel LB. Bombeiros: um olhar sobre a qualidade de vida no trabalho. Psicol Ciência e Profissão [Internet]. 2007 Sep [cited 2017 Dec 6];27(3):554-65. Available from:

http://www.scielo.br/scielo.php?script=sci_arttext\&pid=S1414-

98932007000300014\&lng=pt\&tlng=pt

42. Natividade MR Da. Vidas em risco: a identidade profissional dos bombeiros militares. Psicol Soc. 2009;21(3):411-20.

43. Marconato RS, Monteiro MI. Dor, percepção de saúde e sono: impacto na qualidade de vida de bombeiros/profissionais do resgate. Rev Latino-Americana Enferm [Internet]. 2015 [cited 2017 Dec 6];23(6):991-9. Available from: www.eerp.usp.br/rlae

44. Andrade ER, Sousa ER. Intervenção visando a auto-estima e qualidade de vida dos policiais civis do Rio de Janeiro. Ciênc saúde coletiva. 2009;14(1):275-85. 
45. Vasconcelos TS. Programas de gerenciamento do estresse e qualidade de vida no trabalho na área de segurança pública. In: Stress e qualidade de vida no trabalho: stress social - enfrentamento e prevenção. São Paulo: Atlas; 2011. p. 110-26.

46. Cano I, Duarte TL, Fernandes AO, Silva PS, Ribeiro E. Análise Comparativa das Legislações Disciplinares das Corporações de Segurança Pública: uma proposta de Matriz de Lei Disciplinar para o Brasil. In: Brasil M da J, editor. Pensando a Segurança Pública: direitos humanos [Internet]. Brasília: Ministério da Justiça; 2013 [cited 2017 Dec 6]. p. 30382. Available from: https://www.novo.justica.gov.br/sua-seguranca/segurancapublica/analise-e-pesquisa/download/pensando/pensando-a-seguranca-publica_vol2.pdf/view

47. Amador FS, Santorum K, Cunha CS, Braum SM. Por um programa preventivo em saúde mental do trabalhador na Brigada Militar. Psicol Ciência e Profissão [Internet]. 2002 Sep [cited 2017 Dec 6];22(3):54-61. Available from:

http://www.scielo.br/scielo.php?script=sci_arttext\&pid=S1414-

98932002000300009\&lng=pt\&tlng=pt

\section{Colaboradores}

Todas as autoras contribuíram com a concepção, elaboração, redação, revisão e aprovação do artigo.

Futino RS, Delduque MC. Saúde mental no trabalho de segurança pública: estudos, abordagens e tendências da produção de conhecimento sobre o tema. Cadernos Ibero-Americanos de Direito Sanitário. 2020 abr./jun.; 9(2): 116-134.

http://dx.doi.org/10.17566/ciads.v9i2.632 